\title{
GIDDENS, A. MUNDO EM DESCONTROLE. TRAD. M. L. S. DE A. BORGES. RIO DE JANEIRO: RECORD, 2000, 108 PÁGS.
}

\section{Resenhado por: Marta C. de Noronha Pacheco}

Anthony Giddens, sociólogo britânico da contemporaneidade, possui, na condição de autor ou editor, 31 livros publicados em 22 idiomas. Além de diretor da London School of Economics e professor da Universidade de Cambridge, atua como professor visitante e conferencista em instituições renomadas de diversos países.

Mundo em descontrole compreende as Conferências Reith da BBC proferidas por Giddens em 1999. Tais palestras foram apresentadas a um público convidado e, de modo inovador, em um circuito mundial. A primeira e a última conferência, cujos temas foram globalização e democracia respectivamente, aconteceram em Londres. As palestras sobre risco, tradição e família, seguindo essa mesma ordem, foram gravadas em Hong Kong, Nova Dehli e Washington.

O livro focaliza a globalização e as mudanças dela decorrentes. A globalização é nova, revolucionária, econômica, política, tecnológica e cultural. O desenvolvimento dos sistemas de comunicação na década de 60 a comunicação instantânea, por satélite, entre pontos extremos do planeta - foi um fator importante em sua constituição. Também originando grandes transformações estão as influências econômicas, moldadas por tecnologia, difusão cultural e decisões governamentais de liberalizar e desregulamentar economias nacionais. Giddens chama de pessimista a visão da globalização como "ocidentalização" ou "americanização"; admite, entretanto, que estatísticas, referentes ao período 1989-98, mostram um maior empobrecimento das nações mais pobres. Não obstante, destaca que está ocorrendo um processo de descentralização da globalização e de "colonização inversa”, a influência de países não-ocidentais no Ocidente. Sua crítica recai ainda sobre o protecionismo econômico como forma de resistência à globalização por parte de nações ricas e pobres - trata-se aí de uma estratégia que só se torna necessária em determinados países e momen- 
tos, não devendo ser permanente. Giddens chama nosso olhar para o interior das instituições, nação, família, trabalho, tradição, natureza, denominando-as de "instituições-casca": por fora apresentam-se como antes; por dentro, contudo, sofreram enormes transformações.

O conceito de risco é associado por Giddens a sociedades orientadas para o futuro, que agem para romper com seu passado - um marcador da civilização industrial moderna. Ele vê a aceitação do risco como dinâmica mobilizadora, condição para prazeres e prosperidade, riqueza na economia moderna, e segue-se a ele o desenvolvimento dos sistemas de seguro, base para a assunção de riscos em que o destino perde sua posição para um futuro planejado. O entendimento do risco, essa idéia atrelada à modernidade, é proposto a partir de uma distinção: risco externo, advindo da fixidez da tradição ou da natureza; e risco fabricado, criado pela ação humana sobre o mundo, situações acerca das quais há pouca vivência histórica. Este último abrange também o casamento e a família, mas consiste principalmente em risco ambiental, fruto da crescente globalização. No momento em que se transfere a inquietação humana da ação da natureza sobre o ser humano para a ação do ser humano sobre a natureza, dá-se a transição do risco externo para o fabricado. É dado destaque à expansão do risco, cujo efeito é o surgimento de algo mais arriscado. Seu nível não pode ser mensurado, e a descoberta de conseqüências danosas poderá chegar com atraso. Surgem, então, posições antagônicas: acobertamento e alarmismo. Entre ambas, evidencia-se o caráter fluido da ciência, pontuado por dados científicos e tecnológicos conflitantes e mutáveis. Uma solução é o "princípio de acautelamento", que se relaciona ao limite de responsabilidade. No entanto, não há opção incontestável, trata-se de um problema de administração de risco. Giddens sugere, como possível forma de redução de conseqüências mais graves, mais meios públicos de envolvimento com a ciência e a tecnologia, em lugar de, simplesmente, ser adotada uma atitude negativa em relação ao risco.

Acerca da tradição, Giddens afirma que muito do que se pensa ser tradicional é um produto recente, de no máximo dois séculos, citando o exemplo de países que a têm invocado; para ele, toda tradição é inventada. Na visão iluminista, ela não é mais que o lado sombrio da modernidade. Giddens ressalta, porém, que a idéia de tradição foi criada na modernidade, 
mas sua construção antecede esse período, tendo em vista que tradições e costumes sempre consistiram em meios de poder. Observa ainda que tradições não são imutáveis, ao contrário, são inventadas e reinventadas distinguem-nas o ritual, a repetição e um tipo de verdade definido por elas. Com a globalização, a tradição, apontada no livro como a base do conservadorismo, está perdendo espaço nas instituições públicas e na vida cotidiana. Ocorrem interseções entre tradição e ciência, momentos em que a tradição ressurge e, mais freqüentemente, em que ela acaba por esvaziar-se. Todavia, Giddens reconhece a necessidade de algumas tradições, entre elas as intelectuais, que dão direcionamento e foco às idéias, salientando a importância de se explorarem sempre os limites das tradições necessárias. Outro aspecto assinalado é que, assim como a ausência da tradição impulsiona o ser humano para uma vida mais aberta e reflexiva, a necessidade de tomar decisões, decorrente de autonomia e liberdade, acaba por aumentar dependências e compulsões. A dependência equipara-se à tradição quanto à influência do passado e ao papel-chave da repetição. Entrelaçando idéias, o autor de Mundo em descontrole chega à individualidade, atingida nesse emaranhado de transformações: quando há o declínio da tradição, o senso de identidade tem de ser ativamente criado e recriado - popularizam-se, então, nos países ocidentais, terapias e aconselhamentos; prevalecendo as tradições, a estabilidade das posições sociais dos indivíduos na comunidade sustenta o senso de identidade.

$\mathrm{Na}$ esteira da globalização, um fenômeno que atinge eventos cotidianos e globais com a mesma força, assuntos como sexualidade, casamento e família suscitam extensas análises de Giddens. Também os relacionamentos pessoais estão sofrendo uma revolução global e compreendem vantagens e problemas. Discutem-se hoje intensamente igualdade sexual, regulação da sexualidade e o futuro da família. A família revela-se um local de luta entre tradição e modernidade. Intrínsecas à família tradicional estão as questões de desigualdade entre homens e mulheres, sexualidade feminina, homossexualismo. Giddens atribui à separação entre sexualidade e reprodução a aceitação crescente do homossexualismo. Segundo ele, as mudanças ocorridas em relação ao casamento e à família dão-lhes o caráter de "instituições-casca". A família passou de entidade econômica a união fundamentada no amor romântico e tomou formas di- 
versas. Predomina hoje a família nuclear, e a base principal da unidade do casal encontra-se na comunicação (ou intimidade) emocional. O casamento, mesmo que ainda permaneça como condição normal, não define mais a união como sua base principal. Os filhos representam hoje encargo financeiro; tê-los, portanto, passou a compreender uma decisão mais elaborada. Nessa perspectiva da comunicação emocional, Giddens analisa três áreas de relacionamentos - sexuais e de amor, de pais e filhos e de amizade - valendo-se do que ele chama "relacionamento puro". Este, calcado na comunicação emocional e na confiança mútua, seria implicitamente democrático. Giddens firma, então, um paralelo do relacionamento puro com a democracia pública e apresenta quatro valores equivalentes presentes em ambos: respeito mútuo (estabelecem-se entre iguais ("todos são iguais em princípio”) e compreendem igualdade de direitos e de responsabilidades); diálogo aberto (discussão aberta de questões para compreensão do ponto de vista do outro); confiança mútua; e isenção de autoritarismo, coerção e violência. Delineia-se, daí, uma democracia emergente das emoções - igualdade sexual e liberdade sexual das mulheres.

Quando se refere à democracia, Giddens salienta o poder dos meios de comunicação. A democracia, a seu ver, impulsionou revoluções, mas, nas de 1989 na Europa Oriental, sua influência foi maior em razão de sua difusão, com a ampliação das comunicações globais. Outro fator considerado por Giddens, em sua exposição a respeito de democracia, é que a democracia tem avançado sobremaneira por ser o melhor sistema. Pondera ele sobre o desânimo de algumas pessoas, em especial jovens, acerca dos processos democráticos - ele enfatiza que elas perderam parte da fé nos políticos, mas não nos processos democráticos; comandos autoritários não despertam interesse. Os mais jovens interessam-se mais por questões como ecologia, direitos humanos, política de família e liberdade sexual e menos por questões econômicas, por vê-las como forças que ultrapassam o estado-nação. Os países democráticos, na opinião de Giddens, devem tornar a democracia mais profunda e transnacional - aprofundar a democracia significa democratizá-la, isto é, descentralizar o poder e estabelecer medidas anticorrupção, reforma constitucional e maior transparência nos assuntos políticos, tudo de maneira efetiva, além de promover forte cultura cívica. A sociedade civil, situada entre os outros dois setores 
da sociedade - Estado e mercado -, é a base cultural do governo que, por outro lado, pode fomentá-la. Também a mídia tem papel relevante na democratização: tanto ela é uma força democratizante considerável, quanto, por banalizar e personalizar questões políticas, tende a fechar o espaço público que abre.

De modo coerente, Giddens apresenta conclusões, fazendo, no texto, um caminho da globalização à democracia. Ele aponta a expansão da democracia e também os limites impostos às estruturas democráticas como resultados da globalização. A globalização é um conjunto complexo de processos. Mesmo com a aparência negativa de ocidentalização ou americanização, ela consiste em mudanças de circunstâncias de vida, por meio das quais se encontra em processo de constituição uma sociedade cosmopolita global. Essa sociedade inovadora e a economia dinâmica de que precisa têm como elemento essencial a busca ativa do risco - é necessário discipliná-lo, não negá-lo. Fechando o círculo, Giddens relaciona à democracia emergente das emoções a família e a tradição, conceitos estes incompatíveis com a liberdade sexual das mulheres e a igualdade dos sexos. Transformações nessa área fazem-se necessárias para que haja felicidade e realização pessoal. As instituições democráticas mostram-se essenciais no sentido de possibilitar o governo maior de que necessita o mundo em descontrole.

Ao falar de globalização como uma "tese de que agora vivemos todos num único mundo", Giddens faz um primeiro fracionamento analítico: divide parcela dos pensadores em céticos - aqueles que questionam tudo sobre ela e não vêem grande diferença na economia de hoje - e em radicais - os que crêem na concretude da globalização e em suas conseqüências destrutivas. Outra divisão feita pelo autor é entre fundamentalistas e cosmopolitas, situando-se ele mesmo entre estes últimos.

De certa maneira, essas divisões parece-me aproximarem-se do discurso "totalizante" ${ }^{1}$ do modernismo universal. No entanto, o conteúdo abordado trata de assuntos absolutamente pós-modernos - diferença, fragmentação, indeterminação - suscitados pela revolução compreendida na globalização.

${ }^{1}$ Harvey, 2000:19. 
Há diversos pontos na argumentação de Giddens que são compactuados por $\mathrm{Hall}^{2}$, no que diz respeito à identidade. Hall refere-se ao uso do termo etnia de forma "fundacional" como sendo um mito. Ele afirma não haver uma identidade cultural unificada, serem as nações modernas híbridos culturais e a raça uma categoria discursiva. Na mesma direção, segue Rouanet ${ }^{3}$ ao destacar a relevância de considerar-se uma concepção multiidentitária "a mais importante das nossas identidades, a identidade humana, que partilhamos com todos os habitantes do planeta".

De maneira um pouco mais acautelada, Hall mostra outras possibilidades como conseqüência da globalização, entre elas o fortalecimento de identidades locais e a produção de novas identidades. Cabe aqui uma referência ao fundamentalismo, severamente criticado por Giddens. Hall cita que alguns analistas consideram o fenômeno "uma reação ao caráter 'forçado' da modernização ocidental”. O nacionalismo e outras formas de particularismo se afigurariam, portanto, como uma resposta inesperada aos acontecimentos ligados à globalização ${ }^{4}$.

Uma última observação que faço é quanto à exaltação da democracia feita por Giddens. Nas palavras de Marilena Chaui, "no centro do discurso político capitalista encontra-se a defesa da democracia". Em ambos os casos, quando vista como bem e quando vista como mal, tornou-se "um tipo de governo e um instrumento ideológico para esconder o que ela é, em nome do que ela vale"5.

As afirmações de Giddens são inegavelmente fruto de pesquisa meticulosa e responsável. Meus questionamentos devem-se, todavia, a uma forma reveladamente persuasiva predominante em seu texto (provavelmente por se tratar cada capítulo de uma conferência aberta a um público determinado). Parece ser esse o caso de sua conclusão:

\footnotetext{
${ }^{2}$ A identidade cultural na pós-modernidade, 1999:62-5.

3 Saudades de Roma.

${ }^{4}$ Hall,1999:87-97.

${ }^{5}$ Convite à filosofia, 1995:429-30.
} 
Nada acontece sem luta. Mas a promoção da democracia em todos os níveis é uma luta que vale a pena empreender e ela pode ser vitoriosa. Nosso mundo em descontrole não precisa de menos, mas de mais governo - e este, só instituições democráticas podem prover. (p.91)

Não obstante, vejo como indispensável a leitura de Mundo em descontrole, por se tratar de conteúdo essencial ao entendimento do que vivemos hoje, na modernidade tardia, com o evento da globalização, principalmente acerca da nossa identidade.

\section{REFERÊNCIAS BIBLIOGRÁFICAS}

Chaui, M. Convite à filosofia. 5. ed. São Paulo: Ática, 1995.

Hall, S. A identidade cultural na pós-modernidade. Trad. T. T. da Silva e G. L. Louro. $3^{a}$ ed. Rio de Janeiro: DP\&A, 1999.

Harvey, D. Condição pós-moderna. Trad. A. U. Sobral e M. S. Gonçalves. 9a ed. São Paulo: Loyola, 2000.

Rouanet, S. P. Saudades de Roma. Folha de S. Paulo, São Paulo, 10 junho 2001. Mais!, pp.15-6. 